\title{
Myanmar needs to strengthen smokeless tobacco control polices
}

\author{
Soe Htet Aung
}

$\mathrm{PhD}$ Candidate, Faculty of Tropical Medicine, Mahidol University, Thailand. Assistant Lecturer, Department of Preventive and Social Medicine, Defense Services Medical Academy, Yangon, Myanmar.

Consumption of Smokeless Tobacco (SLT) in the member countries of WHO SEAR region shows upward trends and about $90 \%$ of global smokeless tobacco users are in this region. ${ }^{1}$ Similarly, use of SLT products is highly prevalent in Myanmar which struggles to kick a deadly smokeless tobacco addition. ${ }^{2}$ Sentinel Prevalence Studies of Tobacco Use had been conducted since 2001 which revealed that the prevalence of smoking was slowly declined. Contrary to smoking, the prevalence of consumption of SLT products e.g. chewing of betel quid was raising dramatically in Myanmar according to the surveys conducted in 2001, 2004 and 2007. ${ }^{3}$ According to the nationwide NCD survey (2014), $62 \%$ of men and $24.1 \%$ of women were SLT users. ${ }^{4}$ Global Youth Tobacco Surveys (GYTS) conducted in 2011 among the 13-15 years old students and found that $6.8 \%$ of students were cigarette smokers and $17.4 \%$ of students were any other types of tobacco users. ${ }^{5}$

Chewing Kun Yar (betel quid) constitutes popular activity and offering the betel quid is ceremonial and deeply rooted in Myanmar culture. These are essential and important to treat to the guests at weddings and any other ceremonies. ${ }^{6}$ Growing betel nuts and betel vine leaves are profitable business and many growers called 'Green Gold Business'. 3 On the other hand, there is considerable import of SLT products through legal and illegal means, reflect the increased SLT consumption in the country. ${ }^{7}$ The inflow of illegal tobacco products created a huge loss in tax revenue. ${ }^{8}$ Consequently, uncontrolled proliferation of road side kiosks and stalls emerged in every corner of streets. All SLT products are available with the affordable price without any health warning in Myanmar. The daily household expenditure on for tobacco and cigarettes was $20 \%$ for smokeless tobacco products and $12 \%$ for cigarettes among the low income group.

SLT contains many carcinogenic and toxic substances. ${ }^{10}$ People who chew betel nut are 10 times more likely to have oral cancer than those who do not. ${ }^{11}$ In Myanmar, oral cancer is the second most common cancer among males. ${ }^{12}$ Not only oral cancer, about $39.3 \%$ men and $40.1 \%$ of women were attributed to NCDs who were strongly associated with SLT use. ${ }^{13}$

Although Tobacco Control Law was stipulated in $2006,{ }^{14}$ there is less emphasis on the control of SLT products in many places. Under the Union Taxation Law of $2016,{ }^{15}$ a taxation structure for local or imported tobacco products are $120 \%$ commercial tax on cigarettes, $60 \%$ on other tobacco products. However, there is no taxation on locally produced betel nuts and betel vine leaves, there is a commercial tax of $5 \%$ for imported ones. Consequently, it remains the lowest cost and no impact on the sale and consumption. Taxation policy should be implemented and focus on all SLT products with specific references. Moreover, strong legislation need to be implemented with the additional measures and targeting availability and accessibility of SLT products. Besides, national or regional tracking and tracing system should be established for all SLT products that are manufactured in or imported from illicit trade routes. Existing national tobacco law (2006) need to update to outline a comprehensive legislation and that along the line of WHO Framework Convention on Tobacco Control (WHO FCTC) and it should be organized with legislation of other Southeast Asian Countries.

It is vital to plan and implement a need based and culturally relevant comprehensive program to focus on community's beliefs and perception. Community participation is essential for implementation SLT control activities. Ultimately, the implementation of legislation is possible, but it cannot be achieved without active community support.

\section{References}

1. Singh PK. Smokeless tobacco use and public health in countries of South-East Asia region. Indian J Cancer 2014;51(5):1-2.

2. Strangio. Myanmar struggles to kick a deadly addiction, 2014. https://www.pri.org/stories/2014 -08-27/myanmar-struggles-kick-deadly-addiction (accessed Dec 2016)

3. Sein T, Swe T, Toe MM, Zaw KK, Sein TO. Challenges of smokeless tobacco use in Myanmar. Indian J Cancer 2014;51 Suppl 1:S37.

4. Ministry of Health and Sports (MOHS). Report on National Survey of Diabetes Mellitus and Risk Factors for Non-communicable Diseases in Myanmar. Nay Pyi Taw: MOHS (Myanmar), 2014.

5. Ministry of Health and Sports (MOHS). Health in Myanmar. Nay Pyi Taw: MOHS (Myanmar), 2013.

6. Kyaing N, Sein T, Sein A, Than Htike M, Tun A, Shein N. Smokeless tobacco use in Myanmar. Indian J Cancer 2012;49(4):347-51.

7. Bettcher DW, Yach D, Guindon GE. Global trade and health: key linkages and future

Correspondence: Dr. Soe Htet Aung, PhD Candidate, Faculty of Tropical Medicine, Mahidol University, Bangkok Thailand. Assistant Lecturer, Department of Preventive and Social Medicine, Defense Services Medical Academy, Yangon, Myanmar. E-mail: drsoehtetaung@yahoo.com.

South East Asia Journal of Public Health 2016;6(2):1-2 (C) 2016 Aung, publisher and licensee Public Health Foundation Bangladesh. This is an Open Access article which permits unrestricted non-commercial use, provided the original work is properly cited. 
challenges. Bull World Health Organ 2000;78 (4):521-34

8. Liberman J, Blecher E, Carbajales AR, Burke F. Opportunities and risks of the proposed FCTC protocol on illicit trade. Tob Control 2011;20 (6):436-8.

9. Ministry of Health and Sports (MOHS). Brief Profile on Tobacco Control in Myanmar. Nay Pyi Taw: MOHS (Myanmar), 2009.

10. Lee JH. Smokeless tobacco and head and neck cancer: there is risk even without fire. $S \mathrm{D} \mathrm{Med}$ 2009;Spec No:38-9.

11. Win AZ. Myanmar: An Endemic Country for Oral Cancer. N Am J Med Sci 2015;7(8):377-8.
12. Siegel RL, Miller KD, Jemal A. Cancer statistics, 2015. CA Cancer J Clin 2015;65(1):5-29.

13. Mathers C, Fat DM, Boerma JT. The global burden of disease: 2004 update. Geneva: World Health Organization, 2008.

14. State Peace and Development Council. The Control of Smoking and Consumption of Tobacco Product Law. Contract No.: Report No. 5/2006. State Peace and Development Council (Union of Myanmar), 2006.

15. Union Government of Myanmar. Union Tax Law 2016. Pyidaungsu Hluttaw enacted, 2016 Law No. (22/2016).

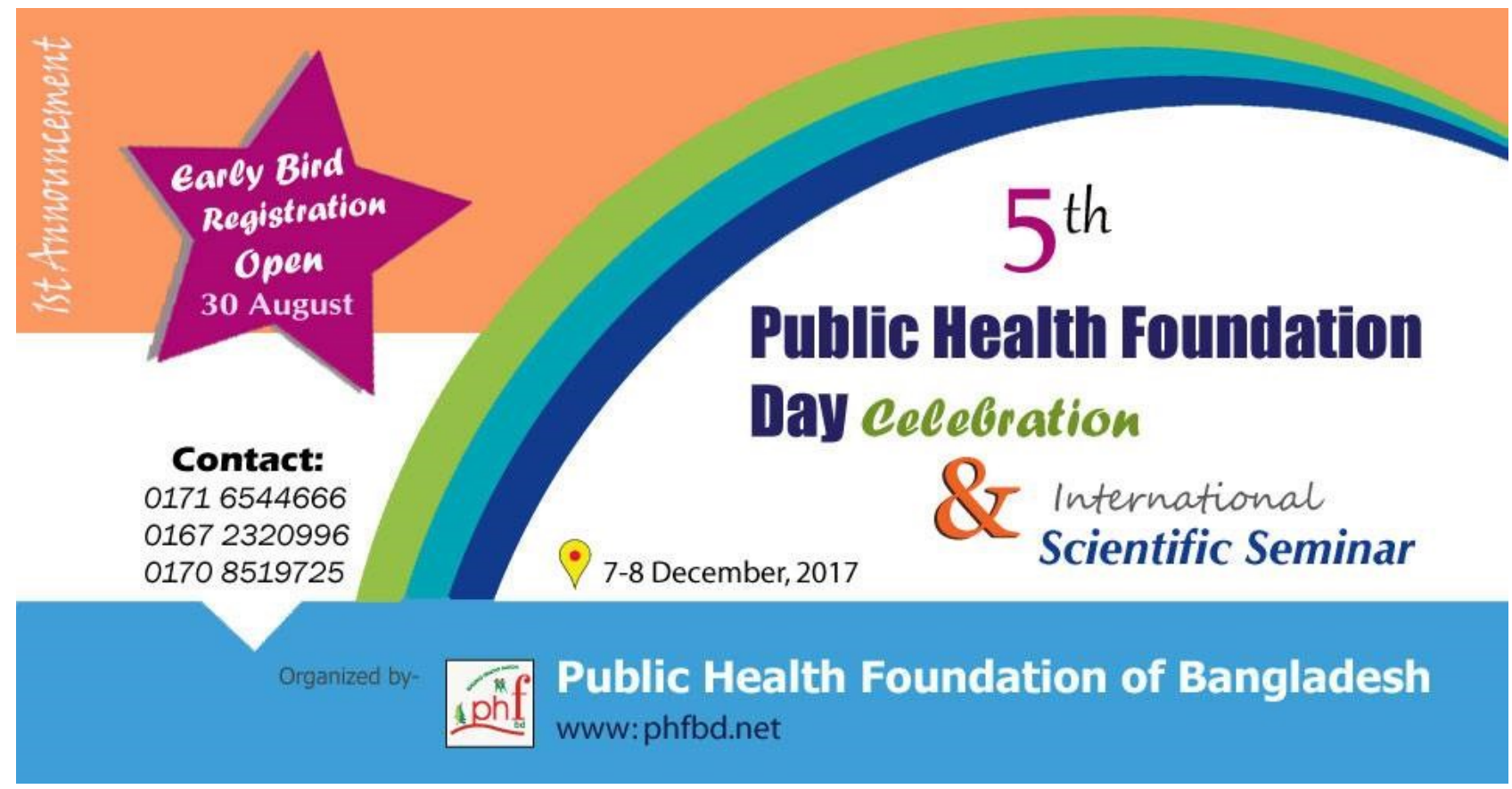

